\title{
Chapter 4 \\ Three-Dimensional Distribution \\ of Radiocesium in Sea Sediment \\ Derived from the Fukushima \\ Dai-ichi Nuclear Power Plant
}

\author{
Daisuke Ambe, Hideki Kaeriyama, Yuya Shigenobu, Ken Fujimoto, \\ Tsuneo Ono, Hideki Sawada, Hajime Saito, Mikiko Tanaka, Shizuho Miki, \\ Takashi Setou, Takami Morita, and Tomowo Watanabe
}

\begin{abstract}
This section introduces results of an investigation for radiocesium $\left({ }^{134} \mathrm{Cs}\right.$ and ${ }^{137} \mathrm{Cs}$ ) in sea sediment. The three-dimensional spatial distributions of radiocesium in sea sediment to a 14-cm core depth were surveyed from off the northern part of Ibaraki Prefecture to off Fukushima Prefecture with 5-min horizontal resolution in July 2012, approximately 16 months after the Fukushima Dai-ichi Nuclear Power Plant (FNPP) accident. A high concentration band was observed along the 100-m isobaths where the
\end{abstract}

D. Ambe $(\bowtie) \bullet$ H. Kaeriyama $\bullet$ Y. Shigenobu $\bullet$ K. Fujimoto $\bullet$ T. Ono

M. Tanaka $\bullet$ S. Miki $\bullet$ T. Setou

National Research Institute of Fisheries Sciences, Fisheries Research Agency,

2-12-4, Fukuura, Kanazawa, Yokohama, Kanagawa 236-8648, Japan

e-mail: Ambe@affrc.go.jp

H. Sawada

National Research Institute of Fisheries Engineering, Fisheries Research Agency,

7620-7, Hasaki, Kamisu, Ibaraki 314-0408, Japan

Maizuru Fisheries Research Station, Field Science Education and Research Center,

Kyoto University, Nagahama, Maizuru, Kyoto 625-0086, Japan

H. Saito

National Research Institute of Fisheries Engineering, Fisheries Research Agency,

7620-7, Hasaki, Kamisu, Ibaraki 314-0408, Japan

Agriculture, Forestry, and Fisheries Council, Agriculture, Forestry and Fisheries Research

Council, 1-2-1, Kasumigaseki, Chiyoda-ward, Tokyo 100-8907, Japan

T. Morita

National Research Institute of Fisheries Sciences, Fisheries Research Agency,

2-12-4, Fukuura, Kanazawa, Yokohama, Kanagawa 236-8648, Japan

Fisheries Agency, 1-2-1, Kasumigaseki, Chiyoda-ward, Tokyo 100-8907, Japan

T. Watanabe

Tohoku National Fisheries Research Institute, Fisheries Research Agency,

3-27-5, Shinhama, Shiogama, Miyagi 985-0001, Japan

e-mail:wattom@affrc.go.jp 
concentration of the ${ }^{137} \mathrm{Cs}$ reached $1,240 \mathrm{~Bq} / \mathrm{kg}$-dry at the maximum and where vertical profiles of the concentration generally had an exponential-type decline with depth. The concentrations were very low at the area shallower than $100 \mathrm{~m}$ of depth north from the FNPP, where vertical concentration peaks often occurred in deeper layers. These horizontal and vertical distribution patterns are suggested to be mainly determined by the supplied amount of radiocesium from the radiocesium-contaminated bottom seawater and the ability of radiocesium adsorption as dependent on the grain size of the sediment.

Keywords Radiocesium $\bullet$ Sea sediment $\bullet$ Grain size $\bullet$ Organic matter $\bullet$ Bottom seawater

\subsection{Introduction}

The Fukushima Dai-ichi Nuclear Power Plant (FNPP) accident associated with the Great Earthquake and ensuing tsunami that occurred east of Japan on March 11, 2011 caused a serious discharge of anthropogenic radionuclides directly into the sea environment from that site. Although a large part of the FNPP-derived radiocesium $\left({ }^{134} \mathrm{Cs}\right.$ and $\left.{ }^{137} \mathrm{Cs}\right)$ released directly into the ocean, which was one of the main discharged radionuclides (TEPCO 2012), was transported and diffused to the open ocean by ocean currents (Buesseler et al. 2011; Aoyama et al. 2012; Tsumune et al. 2012; Kaeriyama et al. 2013, 2014), the radiocesium remained with relatively high concentration levels in sea sediment off East Japan (Kusakabe et al. 2013).

Because ${ }^{134} \mathrm{Cs}$ and ${ }^{137} \mathrm{Cs}$ have long half-lives, about 2.06 years and 30.17 years, respectively, these isotopes are of concern about their affects on the marine benthic ecosystems. A report of marine organism monitoring (Wada et al. 2013) indicated that the radiocesium concentrations in demersal fishes tended to have a higher and slower decline than those in pelagic fish. Therefore, evaluation of the impact of the radiocesium in the sea bottom environment on marine benthic ecosystems is strongly and socially required, but detailed distribution of the radiocesium on the sea bottom and its features had been unclear. In this chapter, the three-dimensional distribution of the radiocesium concentration in sea sediment on July 2012, which was reported by Ambe et al. (2014), is introduced. They revealed the detailed spatial distribution of radiocesium in sediments off the northern part of Ibraki Prefecture to Fukushima Prefecture, with 5-min horizontal resolution (Fig. 4.1). Furthermore, they also obtained the vertical structures of radiocesium in sediment to a $14-\mathrm{cm}$ depth from the sea bottom by tubetype sediment core sampling (Fig. 4.2). (For details of the collecting and analyses for the sediment samples, please see the original article.) The discussion by Amber et al. for formative factors of the distribution of radiocesium in sediment is also introduced here.

\subsection{Horizontal Distribution of Radiocesium}

Figure 4.3 shows the obtained distributions of ${ }^{134} \mathrm{Cs}$ and ${ }^{137} \mathrm{Cs}$ concentrations in the 0-1, 1-2, 2-4, 4-6, 6-10, and 10-14 cm layers on July 2012 by Ambe et al. (2014). The ${ }^{134} \mathrm{Cs}$ concentrations were detected at all sampled locations to the $2-4 \mathrm{~cm}$ layer, 


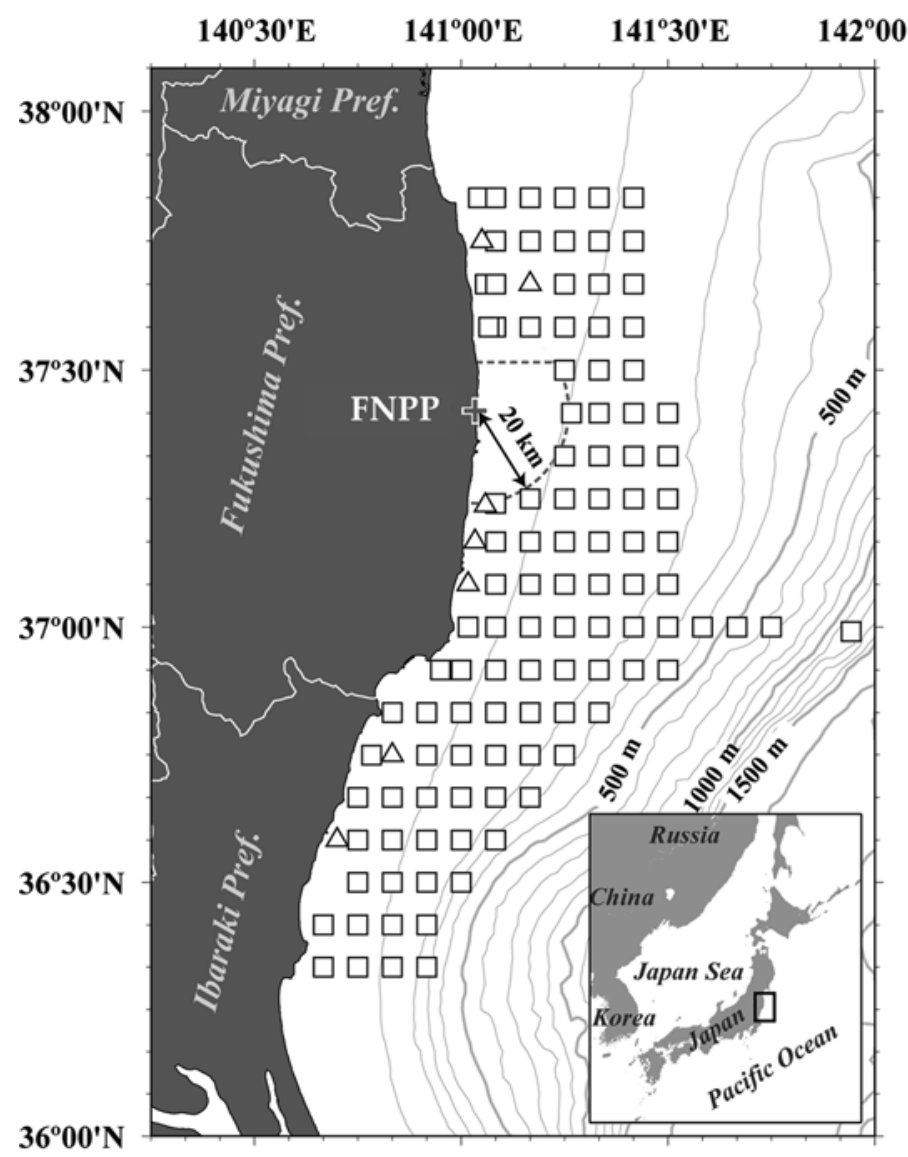

Fig. 4.1 Location of survey for radiocesium concentration in sea sediment in July 2012. Sediments were sampled with a tube-type core sampler (squares) and a Smith-McIntyre grab sampler (triangles). Contour lines indicate water depth at an interval of $100 \mathrm{~m}$. Cross indicates the location of the Fukushima Dai-ichi Nuclear Power Plant (FNPP). Dotted line indicates a caution zone that had been established during the survey period by the Japanese government
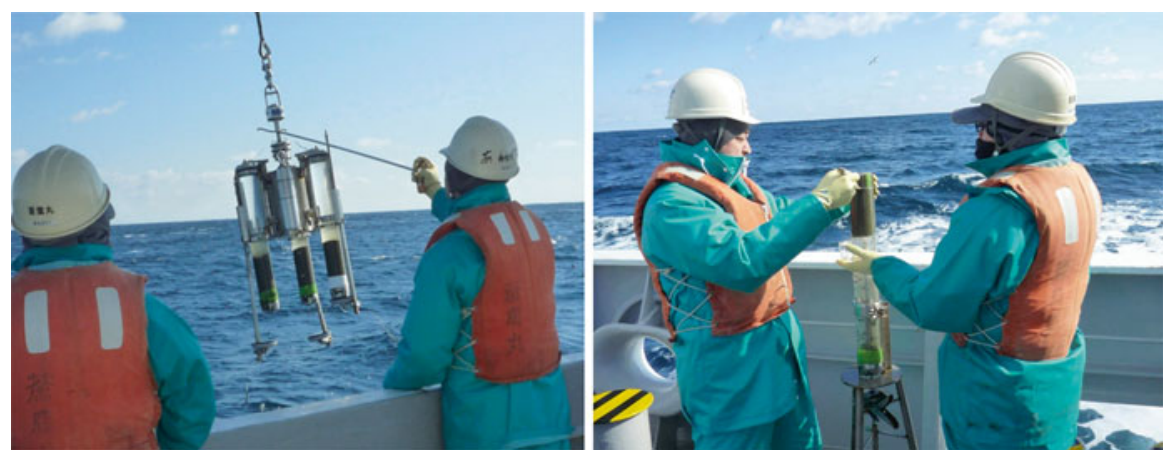

Fig. 4.2 Photographs of collecting sea sediment by a tube-type core sampler 
indicating that radioactive contamination reached this depth by 16 months after the FNPP accident. Although the obtained data were sparse in the deeper layer because of the absence of sediment samplings, they indicated some interesting features of horizontal patterns of radiocesium concentration throughout those sediment layers.

One point is that sediments with relatively high concentrations were distributed along and near the coast and and in 100-m isobaths. For example, concerning the ${ }^{137} \mathrm{Cs}$ concentrations in the $0-1 \mathrm{~cm}$ sediment layer (Fig. $4.3 \mathrm{~g}$ ), where the geometric mean of the concentration value was $100 \mathrm{~Bq} / \mathrm{kg}$-dry in the whole area with a value

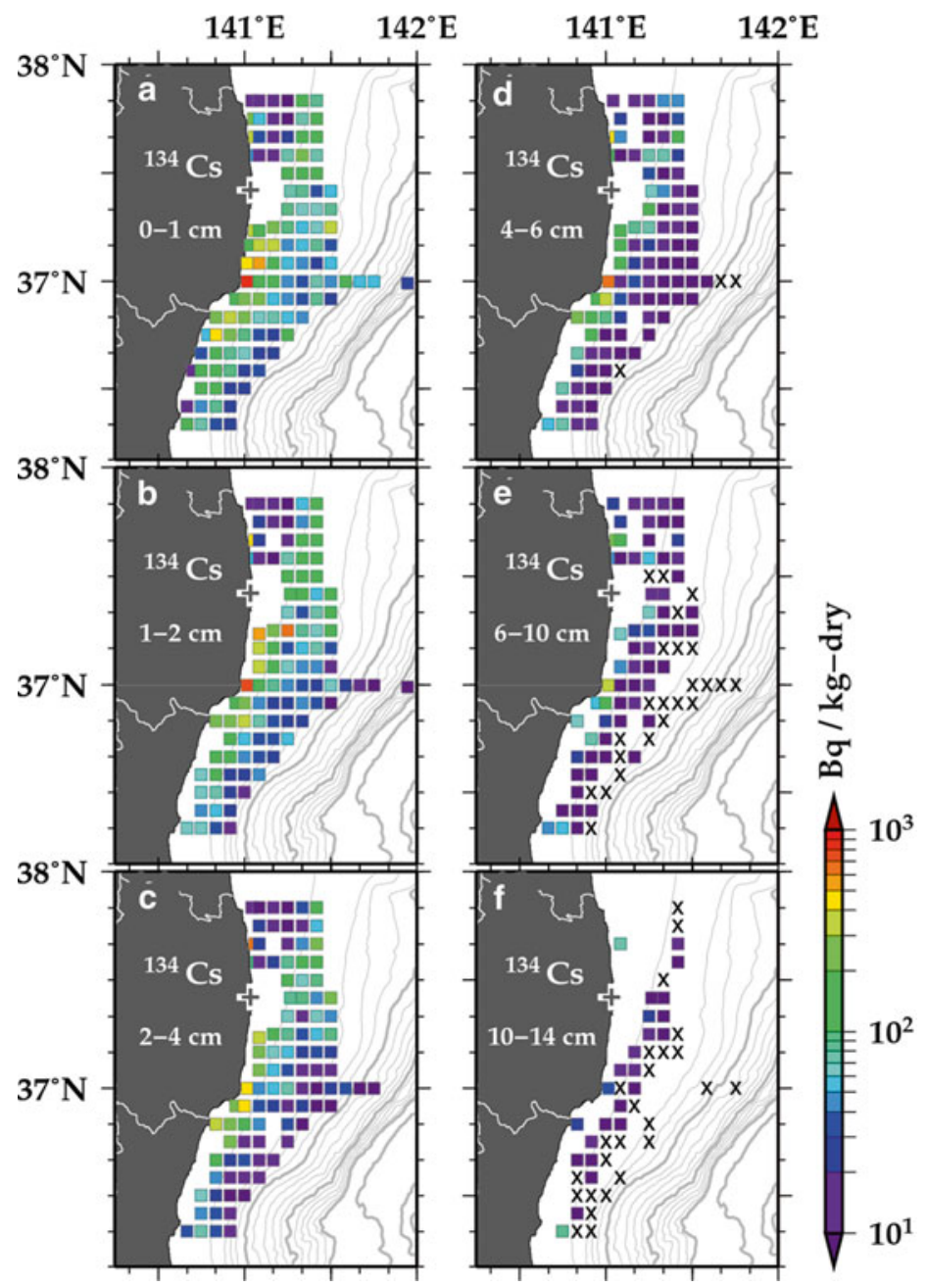

Fig. 4.3 Spatial distributions of ${ }^{134} \mathrm{Cs}(\mathbf{a}-\mathbf{f})$ and ${ }^{137} \mathrm{Cs}(\mathbf{g}-\mathbf{l})$ concentrations in sediment in July 2012. The respective nuclide and layer are indicated at the upper left side of each map. " $\mathrm{X}$ " mean that radiocesium was not detected (concentration was less than the lower limit of detection, which was from 0.63 to $3.0 \mathrm{~Bq} / \mathrm{kg}$-dry). Blank tiles mean data missing where no sample was collected. Contour lines indicate water depth at an interval of $100 \mathrm{~m}$. Cross indicates the location of the FNPP 


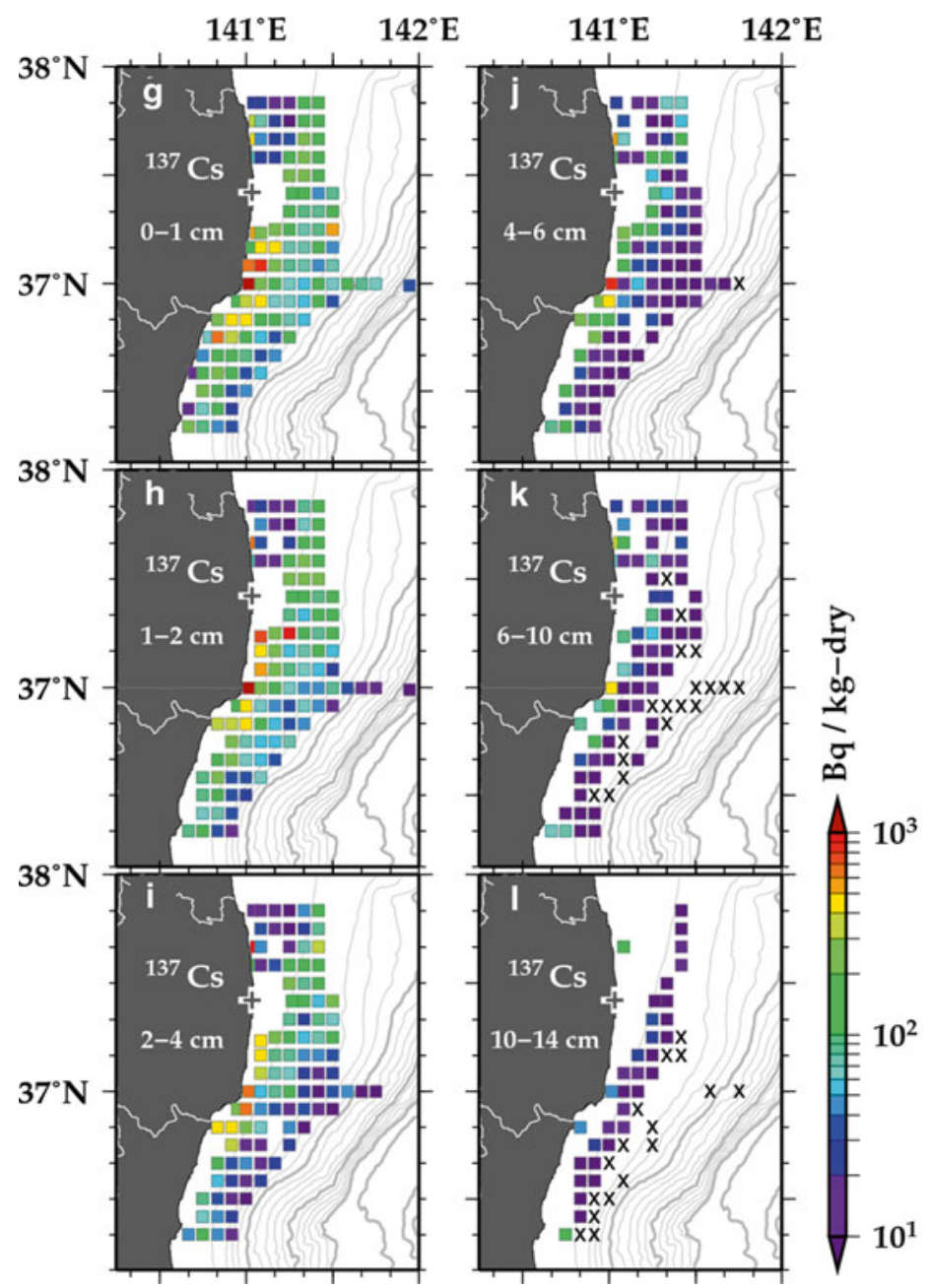

Fig. 4.3 (continued)

range from 8.8 to $1,240 \mathrm{~Bq} / \mathrm{kg}$-dry, most of the concentrations higher than $150 \mathrm{~Bq} /$ kg-dry were distributed in these areas. It can be also seen that the high-concentration bands were divided into two in the northern part of Fukushima Prefecture, associated with the 100-m isobath that goes away from the coast there.

Another significant feature is that sediments with relatively low concentrations were found between the two high-concentration bands in the northern part of Fukushima Prefecture. The concentration value less than approximately $20 \mathrm{~Bq} / \mathrm{kg}$ dry was locally concentrated in this area. Furthermore, a narrow minimal concentration band of 30-60 Bq/kg-dry in the $0-1 \mathrm{~cm}$ sediment layer also seemed to exist near the 200-m isobaths in about 20-30 km east from the high-concentration band in the south of the FNPP. Because this low band did not quite range over plural grid points from east to west, the band width was probably less than $15 \mathrm{~km}$ (for instance, 
a longitudinal 5-min grid interval is approximately $7.4 \mathrm{~km}$ at $37^{\circ} \mathrm{N}$ ). These results indicate that radiocesium concentration does not simply decrease toward offshore.

\subsection{Vertical Distribution of Radiocesium}

Figure 4.4 shows all the acquired vertical profiles of the ${ }^{137} \mathrm{Cs}$ concentrations in the sea sediment in July 2012. Although the ${ }^{137} \mathrm{Cs}$ concentration values ranged widely over two orders of magnitude in each layer, the values from the 25 to 75 percentiles ranged less than one order of magnitude. The median value was the highest in the uppermost layer from the surface $(0-1 \mathrm{~cm})$, and generally exponentially decreased in deeper layers; the median values were 102, 78.3, 46.8, 19.3, 13.1, and $6.54 \mathrm{~Bq} /$ kg-dry in the $0-1,1-2,2-4,4-6,6-10$, and 10-14 cm layers, respectively. Cases wherein the highest concentration was found in the surfacemost layer occupied $53 \%$ of all the profiles. In the remaining cases, the concentration peaks were found in layers deeper than $0-1 \mathrm{~cm}$.

To detect areas with concentration peaks in the deeper layers, all the ${ }^{137} \mathrm{Cs}$ concentration data were converted to relative ratios to ${ }^{137} \mathrm{Cs}$ concentration in the $0-1 \mathrm{~cm}$ layer at each location (Fig. 4.5). It can be seen that relatively high ratios were found near the coast. Ambe et al. (2014) suggested resuspension and redeposition pro-

Fig. 4.4 All obtained vertical profiles (gray lines with circles) of ${ }^{137} \mathrm{Cs}$ concentration in July 2012. The box-andwhisker plot shows the minimum value, the 25 th, 50th, and 75th percentiles, and the maximum value, respectively, in each layer

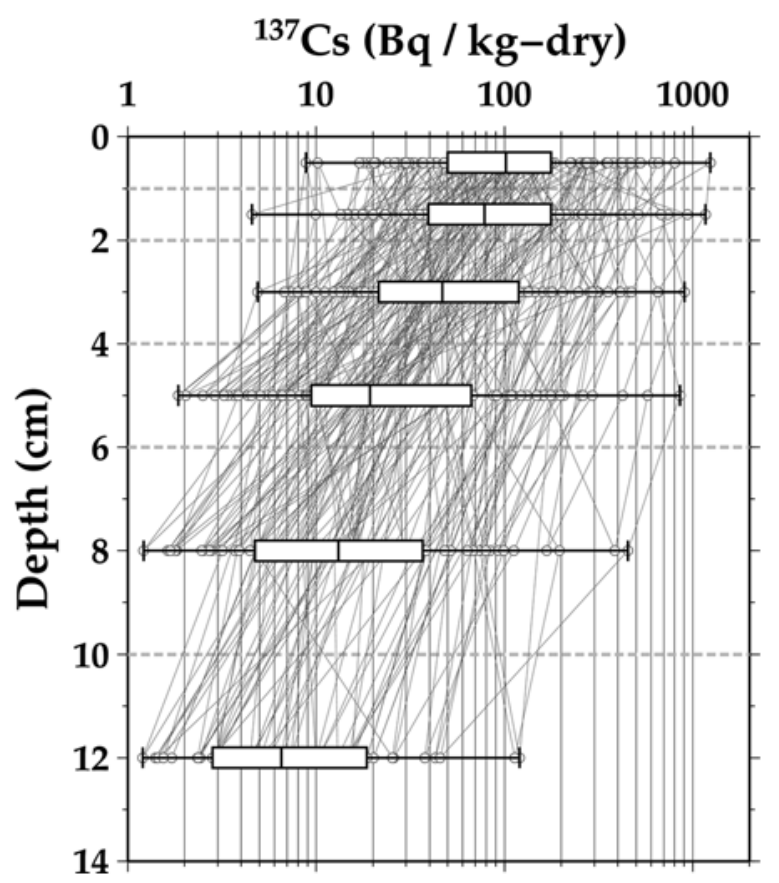


cesses of sediment as possible causes for this factor; that is, in the coastal region, the sea bottom is easily disturbed by ocean waves and bottom currents in general. Therefore, sediment contaminated by radiocesium at the surface and that uncontaminated in deep layers can be mixed or overturned. However, they also suggested another process can operate at the area north of the FNPP where the radiocesium concentrations were very low (Fig. 4.3); the relative ratios were especially high in the deeper layers there. In this regard, a possible factor is introduced with the grain size of sea sediment in the following section.

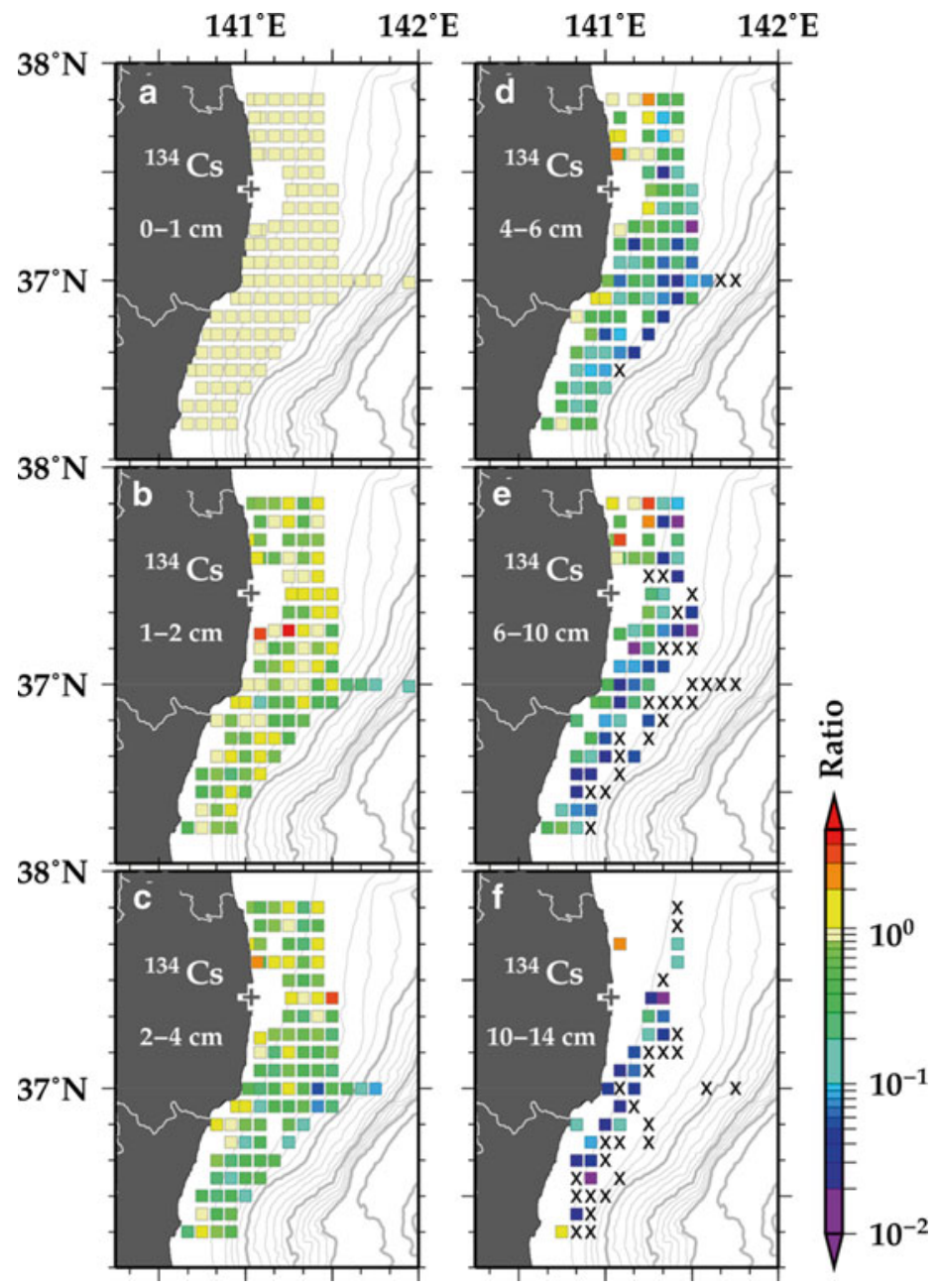

Fig. 4.5 Relative magnitude of ${ }^{134} \mathrm{Cs}(\mathbf{a}-\mathbf{f})$ and ${ }^{137} \mathrm{Cs}(\mathbf{g}-\mathbf{l})$ concentration compared with in the surface-most $(0-1 \mathrm{~cm})$ sediment at each location in July 2012 . The respective layer is indicated at the side of each map 


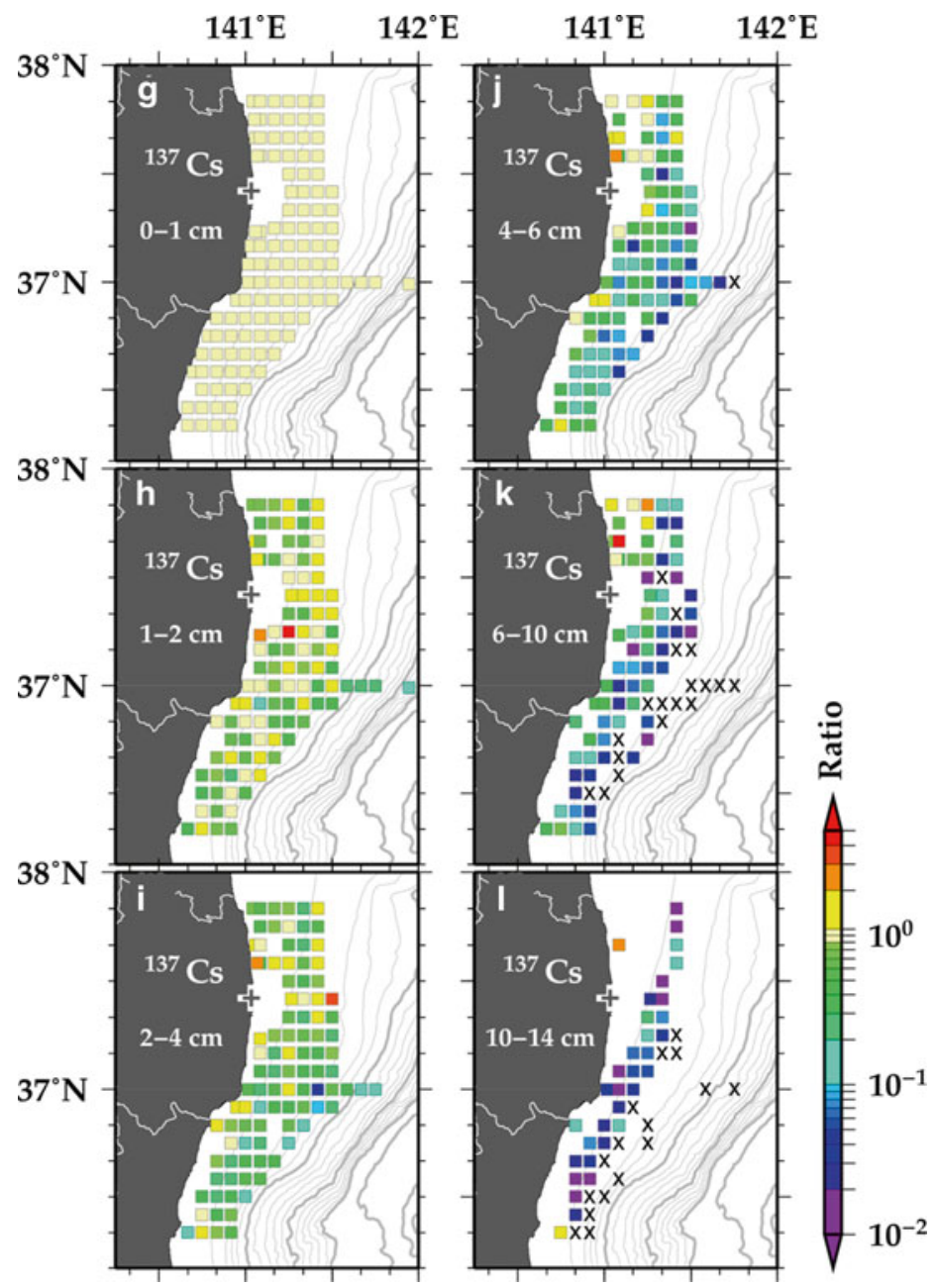

Fig. 4.5 (continued)

\subsection{Grain-Size Distribution and Relationship with Radiocesium Concentrations in Sediment}

Figure 4.6 shows the horizontal distribution of the median grain sizes of sediments in the surface layer $(0-1 \mathrm{~cm})$. Relatively large grain sizes were distributed in the north of the FNPP where the radiocesium concentrations were very low (Fig. 4.3), whereas a band of very small grain sizes, less than $100 \mu \mathrm{m}$ diameter, was found around the $100-\mathrm{m}$ isobaths where the radiocesium concentrations were high (Fig. 4.3). Ambe et al. (2014) further showed a significant correlation between ${ }^{137} \mathrm{Cs}$ 


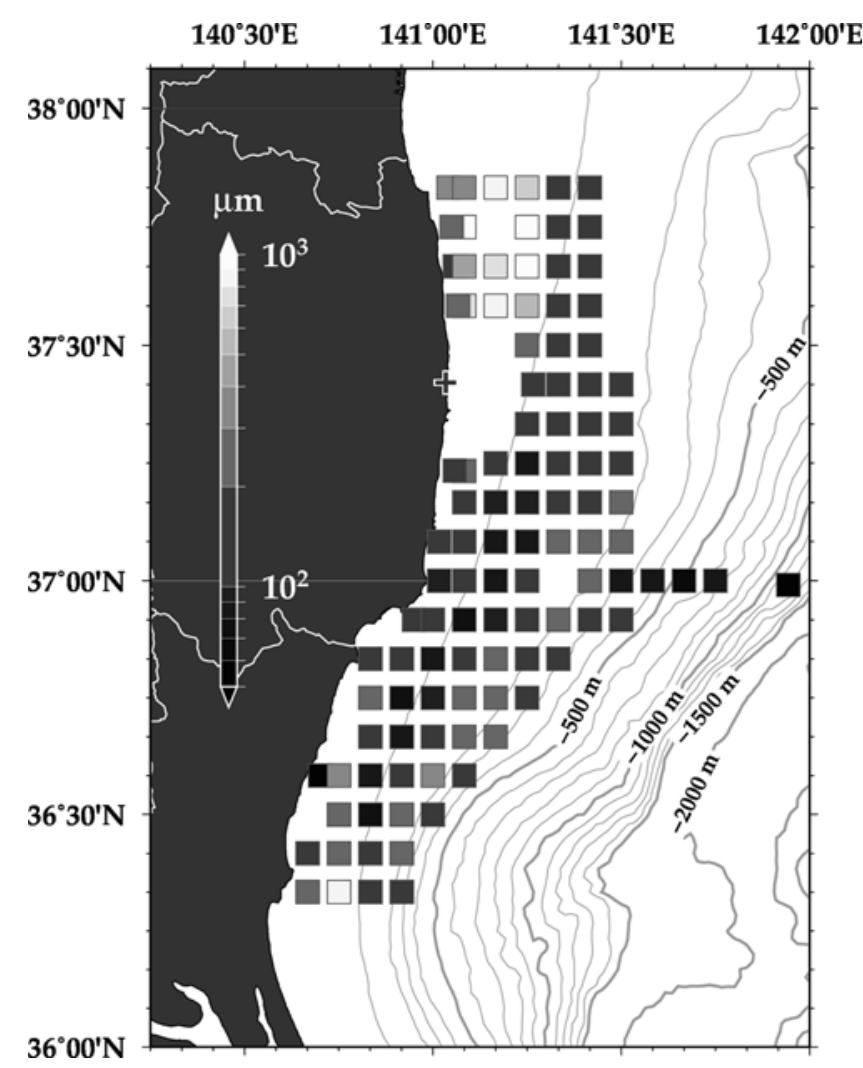

Fig. 4.6 Spatial distribution of median particle grain size of the surface-most sediment in July 2012

concentration and median grain size: the correlation coefficient is $-0.38(p<0.01)$ (Fig. 4.7a). It is well known that Cs has strong affinity with fine minerals, especially illite minerals (Børrentzen and Salbu 2012; Comans et al. 1991; Comans and Hockley 1992; Sakuma and Kawamura 2011). Indeed, by sieving and dividing the surface sediment samples into three grain-size fractions $(<106,106-250$, and $>250 \mu \mathrm{m}$ ), we also obtained similar results, that is, the finer-size fraction of the sediment samples had higher radiocesium concentrations than the bulk sediment in most cases (Fig. 4.8). Thus, the probable grain size-dependent adsorption capability of cesium is strongly suggested as one of the factors that determines the spatial distribution pattern of radiocesium concentration. In addition, as the proportional relationship between the permeability and grain size of sediment is also well known (Shepherd 1989), dissolved radiocesium can migrate downward with seawater through large-grained sediments. Therefore, it can be considered that higher radiocesium concentrations than those in the surface sediment existed in deeper layers at the area north from the FNPP, as indicated in the previous section. 

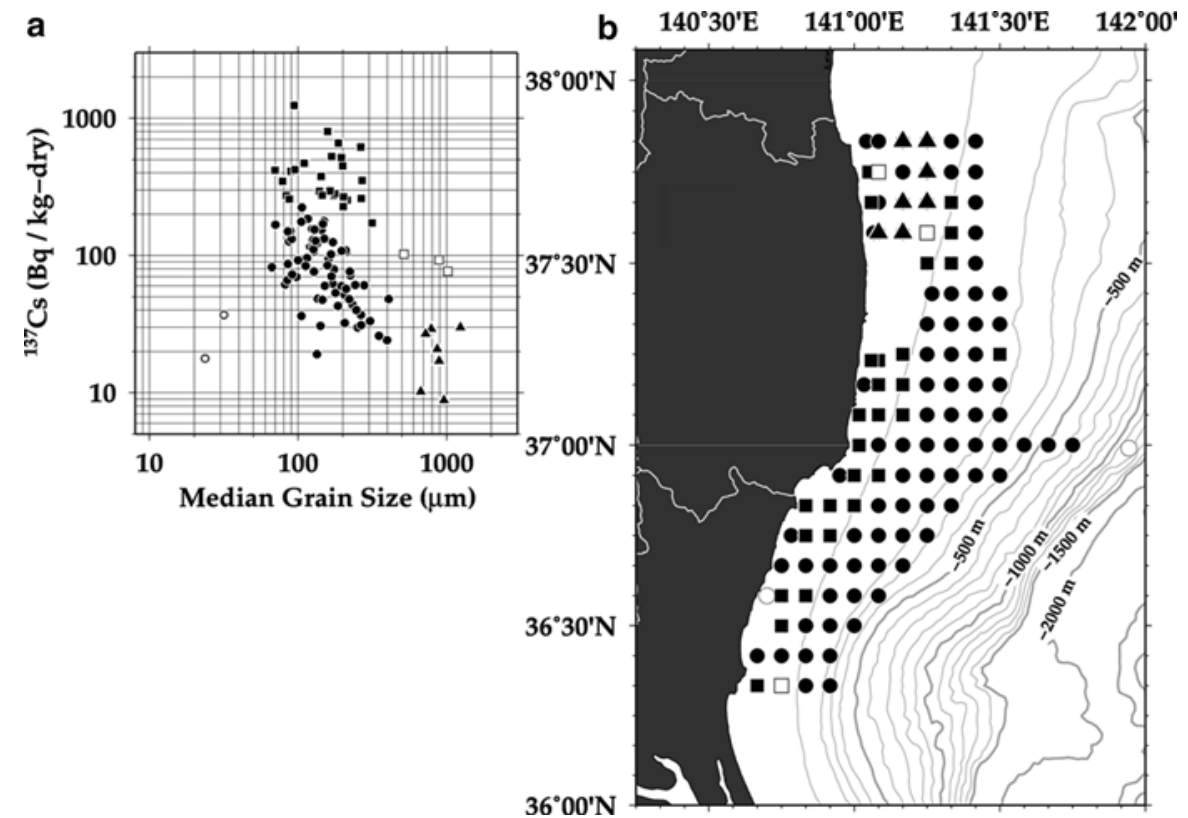

Fig. 4.7 (a) Comparison between ${ }^{137} \mathrm{Cs}$ concentration and median grain size in the most-surface sediment. The symbols for the scatter plot show the clusters segmented into five types by the group average method; the corresponding locations of those types are projected in (b)

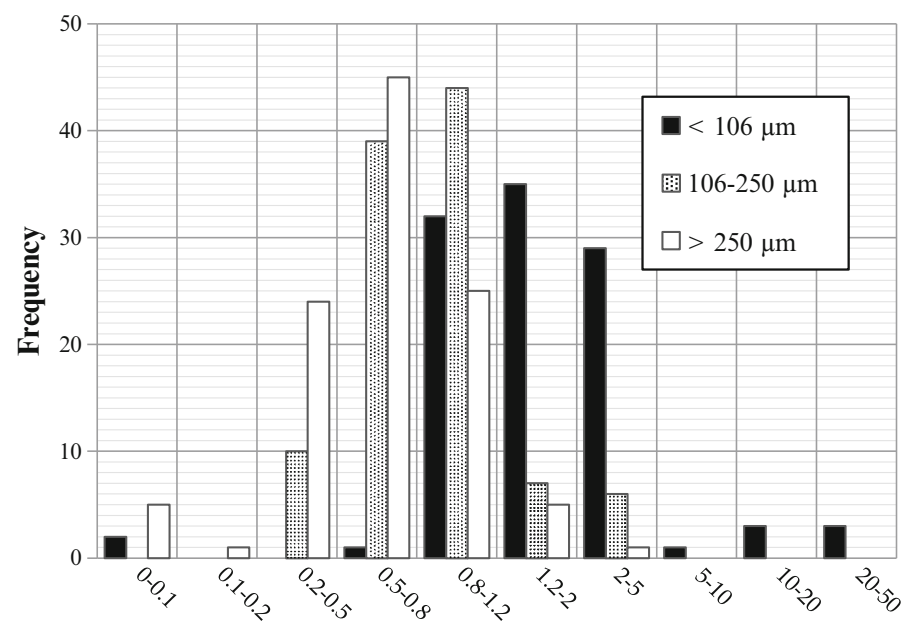

Relative Proportion of ${ }^{137}$ Cs Concentration

Fig. 4.8 Histograms of relative magnitude of ${ }^{137} \mathrm{Cs}$ concentration in each diameter class of the surface-most sediment compared with the concentration in bulk sediment. Diameter classes are indicated at upper right 
Ambe et al. (2014) also indicated that the quantity of radiocesium supplied to the sea bottom from seawater is another factor to determine the distribution of the radiocesium concentration in sea sediment. The concentrations ranged over more than one order of magnitude in each similar grain-size class, but the samples could be divided into five clusters (symbols in Fig. 4.7a) by cluster analysis based on the group average method (Romesburg 2004), using the distance on the coordinate between the median grain size and ${ }^{137} \mathrm{Cs}$ concentration. Accordingly, three types of clusters by geographic dependence were detected (Fig. 4.7b): (1) large grain sizes and low radiocesium concentrations, distributed at depths shallower than $100 \mathrm{~m}$ in the region north from the FNPP (indicated by filled triangles in the figure); (2) small grain sizes with high radiocesium concentrations, distributed mainly at depths shallower than $100 \mathrm{~m}$, excepting the area of cluster (1) (indicated by filled squares); and (3) small grain sizes with low radiocesium concentrations, mainly in the area deeper than $100 \mathrm{~m}$ (filled circles). The division of cluster (1) from others can be attributed mainly to the low adsorption capability of large-grain-size sediment for cesium, as already mentioned. On the other hand, the radiocesium concentration in bottom seawater could be more than twice or one order higher in the area shallower than $100 \mathrm{~m}$ than in the area at 100-300 m depth by monitoring data (Oikawa et al. 2013) and numerical study (Bailly du Bois et al. 2014), for division between the clusters (2) and (3).

\subsection{Organic Matter Content and Relationship with Radiocesium Concentration in Sediment}

Ambe et al. (2014) also investigated the horizontal distribution of the organic matter content in the surface sediment (as shown in Fig. 4.9a). Although notably higher values, up to almost $10 \%$, existed along the 100-m isobaths where the radiocesium concentrations were very low, the content was relatively low north of the FNPP where the radiocesium concentrations were high. These patterns highly corresponded to those of the median grain size. Therefore, the organic matter content also was correlated with the ${ }^{137} \mathrm{Cs}$ concentration $(r=0.38, p<0.01)$ and the median grain size $(r=-0.76, p<0.01)$ (Fig. $4.9 \mathrm{~b})$. This result seems superficially to indicate that organic content also can determine radiocesium concentration. However, a report for radiocesium concentration in the coastal area of Ibaraki Prefecture after the FNPP accident (Otosaka and Kobayashi 2013) indicated that the lithogenic fraction contained most of the ${ }^{137} \mathrm{Cs}$ in the sediment. The contribution of organic matter to the radiocesium concentration in sea sediment is also small by chemical leaching for the samples of Ambe et al. (2014) (as seen in the next chapter). Thus, the organic matter might not be the constitutive factor that determines radiocesium concentration in sea sediment more than 1 year after the FNPP accident. The grain size of sediment could determine the distributions of both the ${ }^{137} \mathrm{Cs}$ concentration and the organic matter content in sediment. 


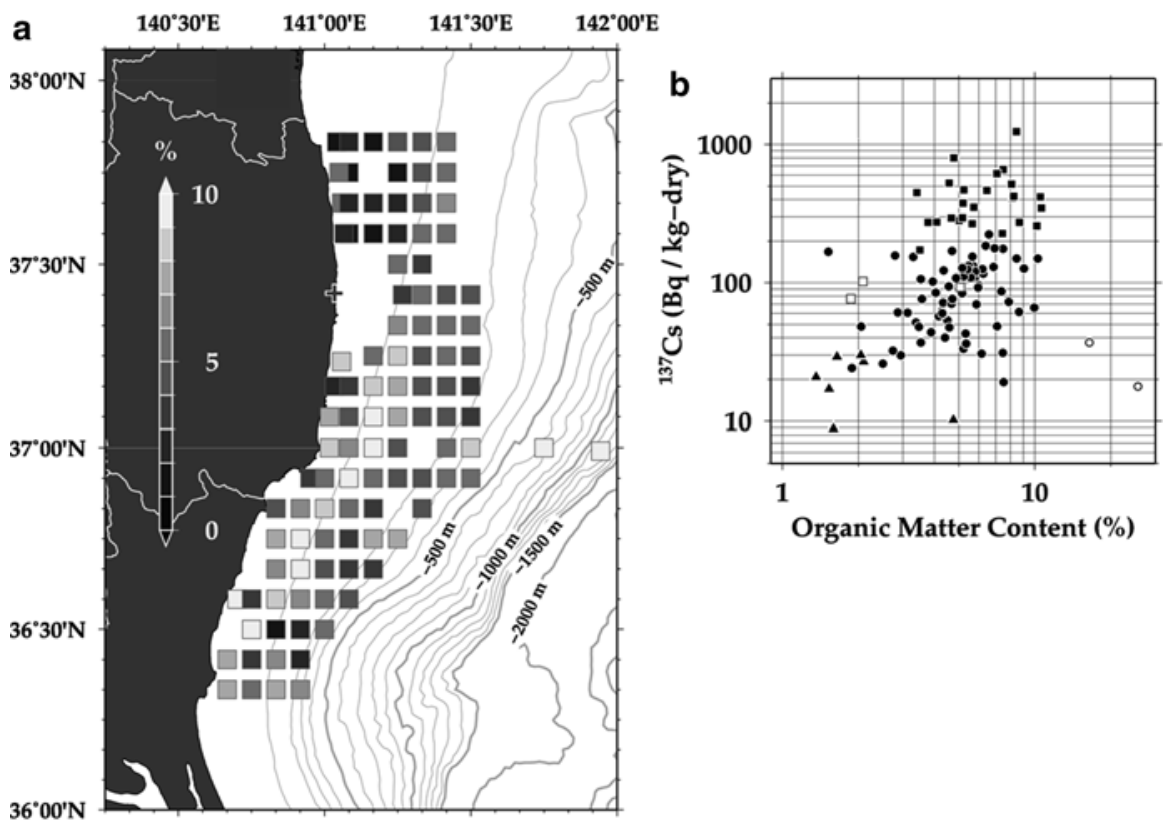

Fig. 4.9 (a) Spatial distribution of organic matter content of the surface-most sediment in July 2012. (b) Comparison between ${ }^{137} \mathrm{Cs}$ concentration and organic matter content in the surface sediment. Symbols correspond to the result of cluster analysis in Fig. 4.7a

Acknowledgments This study was supported by the Fisheries Agency, Ministry of Agriculture, Forestry and Fisheries, Japan.

Open Access This chapter is distributed under the terms of the Creative Commons Attribution Noncommercial License, which permits any noncommercial use, distribution, and reproduction in any medium, provided the original author(s) and source are credited.

\section{References}

Ambe D, Kaeriyama H, Shigenobu Y, Fujimoto K, Ono T, Sawada H, Saito H, Miki S, Setou T, Morita T, Watanabe T (2014) Five-minute resolved spatial distribution of radiocesium in sea sediment derived from the Fukushima Dai-ichi Nuclear Power Plant. J Environ Radioact 138:264-275. doi:10.1016/j.jenvrad.2014.09.007

Aoyama M, Tsumune D, Uematsu M, Kondo F, Hamajima Y (2012) Temporal variation of ${ }^{134} \mathrm{Cs}$ and ${ }^{137} \mathrm{Cs}$ activities in surface water at stations along the coastline near the Fukushima Dai-ichi Nuclear Power Plant accident site, Japan. Geochem J 46(4):321-325

Bailly du Bois P, Garreau P, Laguionie P, Korsakissok I (2014) Comparison between modelling and measurement of marine dispersion, environmental half-time and ${ }^{137} \mathrm{Cs}$ inventories after the Fukushima Daiichi accident. Ocean Dyn 64(3):361-383. doi:10.1007/s10236-013-0682-5

Børrentzen P, Salbu B (2012) Fixation of Cs to marine sediments estimated by a stochastic modeling approach. J Environ Radioact 61:1-20 
Buesseler K, Aoyama M, Fukasawa M (2011) Impacts of the Fukushima Nuclear Power Plants on marine radioactivity. Environ Sci Technol 45:9931-9935

Comans RNJ, Hockley D (1992) Kinetics of cesium sorption on illite. Geochim Cosmochim Acta 56:1157-1164

Comans RNJ, Haller M, DePreter P (1991) Sorption of cesium on illite: non-equilibrium behavior and reversibility. Geochim Cosmochim Acta 55:433-440

Kaeriyama H, Ambe D, Shimizu Y, Fujimoto K, Ono T, Yonezaki S, Kato Y, Matsunaga H, Minami $\mathrm{H}$, Nakatsuka S, Watanabe T (2013) Direct observation of ${ }^{134} \mathrm{Cs}$ and ${ }^{137} \mathrm{Cs}$ in the western and central North Pacific after the Fukushima Dai-ichi Nuclear Power Plant accident. Biogeosciences 10:4287-7295

Kaeriyama H, Shimizu Y, Ambe D, Masujima M, Shigenobu Y, Fujimoto K, Ono T, Nishiuchi K, Taneda T, Kurogi H, Setou T, Sugisaki H, Ichikawa T, Hidaka K, Hiroe Y, Kusaka A, Kodama T, Kuriyama M, Morita H, Nakata K, Morinaga K, Morita T, Watanabe T (2014) Southwest intrusion of ${ }^{134} \mathrm{Cs}$ and ${ }^{137} \mathrm{Cs}$ derived from the Fukushima Dai-ichi Nuclear Power Plant accident in the western North Pacific. Environ Sci Technol 48:3120-3127

Kusakabe M, Oikawa S, Takata H, Misonoo J (2013) Spatiotemporal distributions of Fukushimaderived radionuclides in nearby marine surface sediments. Biogeosciences 10:5019-5030. doi:10.5194/bg-10-5019-2013

Oikawa S, Takata H, Watabe T, Misonoo J, Kusakabe M (2013) Distribution of the Fukushimaderived radionuclides in seawater in the Pacific off the coast of Miyagi, Fukushima, and Ibaraki prefectures, Japan. Biogeosciences 10:5031-5047. doi:10.5194/bgd-10-4851-2013

Otosaka S, Kobayashi T (2013) Sedimentation and remobilization of radiocesium in the coastal area of Ibaraki, $70 \mathrm{~km}$ south of the Fukushima Dai-ichi Nuclear Power Plant. Environ Monit Assess 185:5419-5433. doi:10.1007/s10661-012-2956-7

Romesburg HC (2004) Cluster analysis for researchers. Lulu Press, Morrisville

Sakuma H, Kawamura K (2011) Structure and dynamics of water on $\mathrm{Li}^{+}-, \mathrm{Na}^{+}, \mathrm{K}^{+}-, \mathrm{Cs}^{+}-, \mathrm{H}_{3} \mathrm{O}^{+}-$ exchanged muscovite surfaces: a molecular dynamics study. Geochim Cosmochim Acta 75:63-81

Shepherd RG (1989) Correlations of permeability and grain size. Ground Water 27:633-638. doi:10.1111/j.1745-6584.1989.tb00476.x

TEPCO (Tokyo Electric Power Co.) (2012) TEPCO news press releases. http://www.tepco.co.jp/ en/press/corp-com/release/2012/1204659_1870.html

Tsumune D, Tsubono T, Aoyama M, Hirose K (2012) Distribution of oceanic ${ }^{137} \mathrm{Cs}$ from the Fukushima Dai-ichi Nuclear Power Plant simulated numerically by a regional ocean model. J Environ Radioact 111:100-108. doi:10.1016/j.jenvrad.2011.10.007

Wada T, Nemoto Y, Shimamura S, Fujita T, Mizuno T, Sohtome T, Kamiyama K, Morita T, Igarashi S (2013) Effects of the nuclear disaster on marine products in Fukushima. J Environ Radioact 124:246-254. doi:10.1016/j.jenvrad.2013.05.008 